\title{
Relationship of PD-1 (PDCD1) and PD-L1 (CD274) Single Nucleotide Polymorphisms with Polycystic Ovary Syndrome
}

\author{
Rui Han $\mathbb{D}^{1,2,3}$ Xiaoyun Gong ${ }^{1},{ }^{4}$ Yuejie Zhu $\mathbb{D}^{4},{ }^{4}$ Xiaoran Liu $\mathbb{D},{ }^{1}$ Yan Xia $\mathbb{D}^{1},{ }^{1}$ \\ Yuhong Huang $\mathbb{D}^{2}{ }^{2}$ Meng Zhang $\mathbb{D}^{4}$, Yunian Zhang $\mathbb{D}^{2}{ }^{2}$ Xiaolin La $\mathbb{D}^{4},{ }^{4}$ and Jianbing Ding $\mathbb{D}^{2,3}$ \\ ${ }^{1}$ Department of Prenatal Diagnosis, Reproductive Medicine Center, The First Affiliated Hospital of Xinjiang Medical University, \\ Urumqi, 830011 Xinjiang, China \\ ${ }^{2}$ Department of Immunology, College of Basic Medicine, Xinjiang Medical University, Urumqi, 830011 Xinjiang, China \\ ${ }^{3}$ State Key Laboratory of Pathogenesis, Prevention, Treatment of Central Asian High incidence Diseases, The First Affiliated Hospital \\ of Xinjiang Medical University, Urumqi, 830011 Xinjiang, China \\ ${ }^{4}$ Department of Reproductive Assistance, Center for Reproductive Medicine, The First Affiliated Hospital of Xinjiang \\ Medical University, Urumqi, 830011 Xinjiang, China
}

Correspondence should be addressed to Jianbing Ding; 1601379937@qq.com

Rui Han and Xiaoyun Gong contributed equally to this work.

Received 10 July 2020; Revised 30 November 2020; Accepted 18 December 2020; Published 4 January 2021

Academic Editor: Silvia Gregori

Copyright ( 92021 Rui Han et al. This is an open access article distributed under the Creative Commons Attribution License, which permits unrestricted use, distribution, and reproduction in any medium, provided the original work is properly cited.

\begin{abstract}
This study is to investigate the relationship of programmed cell death 1 (PD-1; also known as PDCD1) and programmed death-1ligand 1 (PD-L1; also known as CD274) single nucleotide polymorphisms (SNPs) with polycystic ovary syndrome (PCOS). This study enrolled 330 PCOS patients and 350 matched controls. ELISA was used to detect the PD-1 and PD-L1 levels in serum. SnaPshot genotyping was performed to analyze the PD-1 and PD-L1 genotyping. Linkage disequilibrium and haplotype of TagSNP loci of PD-1 and PD-L1 genes were also detected. The relationship of genotypes and alleles with PCOS was analyzed. The levels of PD-1 and PD-L1 in the serum of PCOS patients were significantly lower than those in the control group $(P<0.01)$. The haplotype TT of PD-1 gene at rs10204525 and rs7421861 loci was significantly lower in the PCOS group than in the control group $(P<0.001, \mathrm{OR}=0.67$, and 95\%CI $=0.54-0.84)$. PD-L1 gene SNP loci rs2282055, rs2890658, rs10125854, and rs702275 had linkage disequilibrium. The haplotypes TAAA, GAAC, GAGC, GCAA, and TCGA of PD-L1 gene SNP loci were significantly higher in PCOS patients than in the control group, whereas haplotypes GAAA, TAAC, TCAA, GCGA, GCAC, and TCGC of PD-L1 gene SNP loci were significantly lower in PCOS patients than in the control group. PD-1 and PD-L1 SNPs may be related to the pathogenesis of PCOS. PD-1 gene SNP loci rs10204525 and rs7421861 and PD-L1 gene SNP loci rs2282055, rs2890658, rs10125854, and rs702275 may be new candidate polymorphic loci for PCOS.
\end{abstract}

\section{Introduction}

Polycystic ovary syndrome (PCOS) is a metabolic disease of endocrine disorders in women. Its incidence in women of childbearing age is $5 \%-10 \%[1-3]$. PCOS is mainly manifested as abnormal menstruation, infertility, obesity, hairy, polycystic ovarian changes, hyperandrogenemia, insulin resistance, and induced hyperinsulinemia [4]. With the changes in people's lifestyle and environment, the incidence of PCOS has been increasing year by year [5]. At present, the pathogenesis of PCOS is still unclear. Epidemiological survey reveals obvious family clustering characteristics of PCOS [6]. Chen et al. have reported 11 susceptible genes related to PCOS disease and extensively tested them in European and American populations [7]. Therefore, genetic factors play a very important role in the etiology of PCOS.

Programmed cell death 1 (PD-1; also known as PDCD1) and programmed death-1-ligand 1 (PD-L1; also known as CD274) play important negative regulatory roles in inflammation, autoimmune diseases, and tumors. They are widely 
involved in suppressing inflammatory response and tumor immune evasion $[8,9]$. Genetic mutations in PD-1 and PD-L1 not only increase the risk of kidney cancer [10] and thyroid cancer [11], but also are closely related to the course, clinical stage, and metastasis of the tumor and even affect the function of kidney transplantation [12]. In a multicenter meta-analysis by Mohammad et al. [13], it is found that PD-1 and PD-L1 gene polymorphisms were related to susceptibility and progression of all cancers. It is reported that PD-1 and PD-L1 gene polymorphisms can affect the susceptibility to ankylosing spondylitis $[14,15]$. In addition, PD-L1 gene polymorphisms are reported to be associated with lung cancer susceptibility $[16,17]$. Therefore, PD-1 and PD-L1 gene polymorphisms are closely related to the occurrence of diseases such as cancer. However, whether the PD-1 and PD-L1 gene polymorphisms are related to the occurrence and development of PCOS has not been reported.

In this study, we explored the correlation between PD-1 and PD-L1 gene polymorphisms and the pathogenesis of PCOS.

\section{Materials and Methods}

2.1. Patients. This study included 330 patients diagnosed with PCOS at the Reproductive Fertility Center of the First Affiliated Hospital of Xinjiang Medical University. Meanwhile, 350 non-PCOS women of childbearing age who matched the clinical indicators of PCOS patients were recruited as control group. The inclusion criteria for the PCOS patient group included the following: (1) the diagnosis of PCOS met the diagnostic criteria established by the Rotterdam International Conference [18]. Patients with any two items of the following three items can be diagnosed: little or no ovulation, hyperandrogenemia, ovarian volume $>10 \mathrm{~mL}$ on ultrasound imaging, and $\geq 12$ follicles with $2-9 \mathrm{~mm}$ in diameter. (2) The patients did not take drugs that may affect hormones, blood glucose, or insulin at 3 months before the blood collection. (3) The patients did not implement planned weight loss. Exclusion criteria for patients with PCOS included the following: (1) patients with congenital adrenal hyperplasia, Cushing syndrome, and ovarian or adrenal tumors; (2) patients with hyperprolactinemia, thyroid disease, or pituitary tumor; (3) patients with severe primary diseases such as cardiovascular disease, liver disease and kidney disease, or mental illness; (4) patients with pregnancy or suspicious pregnancy, lactation, suffering from other endocrine diseases, with long-term oral contraceptives, or subcutaneous implanted contraception. The inclusion criteria of the control group included the following: (1) patients with infertility due to tubal obstruction or male reasons. (2) Their age, body mass index, and other clinical indicators were matched with those in the PCOS group. (3) They had regular menstruation and normal serum androgens. (4) They had no clinical hyperinsulinemia, no symptoms of hyperandrogenemia, and no clinical manifestations of PCOS such as hairy, acne, and skin seborrhea. Written informed consent was obtained from every patient, and the study was approved by the Ethics Committee of the First Affiliated Hospital of Xinjiang Medical University.
2.2. Detection of Clinical Indicators. We recorded the clinical information of all patients and normal controls, including age, weight, height, waist circumference, and hip circumference. Body mass index was calculated as BMI = weight $(\mathrm{kg}) /$ height $^{2}\left(\mathrm{~m}^{2}\right)$. Waist-to-hip ratio (WHR) was calculated as waist circumference/hip circumference. Peripheral blood (3$5 \mathrm{~mL}$ ) was collected from patients and controls. The serum levels of follicle-stimulating hormone (FSH), luteinizing hormone ( $\mathrm{LH})$, and testosterone $(\mathrm{T})$ were measured using a chemiluminescence immunoassay analyzer (i2000SR, Abbott). Fasting blood glucose (FBG) was measured using hexokinase method (AU5821, Beckman, Germany). Fasting insulin (FNS) was detected by chemiluminescence method (i2000SR, Abbott). The formula for calculating the insulin resistance index (HOMA-IR) is as follows: [HOMA - IR = fasting insulin $(\mathrm{mIU} / \mathrm{L}) \times$ fasting blood glucose $(\mathrm{mmol} / \mathrm{L}) / 22.5]$.

2.3. ELISA. The serum levels of PD-1 and PD-L1 were detected with corresponding ELISA kits (E-EL-H1534c/EEL-H1547c Elabscience Biotechnology Co. Ltd, Wuhan, China) according to the kit instructions. OD450 was measured, and the concentrations of PD-1 and PD-L1 in the specimens were calculated by the standard curve.

2.4. DNA Extraction and Genotyping. DNA was extracted from peripheral blood using TIANamp Blood DNA Kit (TIANGEN, Beijing, China). Data on the linkage disequilibrium between $\mathrm{PD}-1$ and $\mathrm{PD}-\mathrm{L} 1$ gene single nucleotide polymorphisms (SNPs) in the Chinese population were obtained by querying the NCBI database. By setting the linkage disequilibrium coefficient $r^{2}$ of SNP loci $\geq 0.8$ and the minimum allele frequency $>5 \%$ as the standard, we used the Haploview software to select three TagSNP loci representing the four SNP loci of the entire PD-1 gene and 12 TagSNP loci representing 24 SNP loci for the entire PD-L1 gene. Finally, the HapMap map was generated (Figure 1).

2.5. SnaPshot Typing Test. By using the SnaPshot typing technique [19], we detected a total of 15 SNP loci in PD-1 and PD-L1 genes. The sequences of PD-1 and PD-L1 were retrieved through Gene Bank. The primers were designed using the Primer 5.0 software and synthesized by Shanghai Sangon Biotech (China). The primer sequences are shown in Table 1. Briefly, after PCR amplification of the genomic DNA sample, the amplified PCR product $(2 \mu \mathrm{L})$ was purified and mixed with $1 \mu \mathrm{L}$ SnaPshot Mix and $0.2 \mu \mathrm{L}$ primers, and then, the reaction system was supplemented with $\mathrm{ddH}_{2} \mathrm{O}$ to $6.0 \mu \mathrm{L}$ to perform PCR reaction. Then, $1 \mu \mathrm{L}$ of the product was taken, and $9 \mu \mathrm{L}$ of the loading $\mathrm{Hi}-\mathrm{Di}$ was added. The samples were denatured at $95^{\circ} \mathrm{C}$ for $3 \mathrm{~min}$, and an ice-water bath was performed immediately. After that, the sample was added with $\mathrm{Hi}$-Di Formamide $9 \mu \mathrm{L}$, denatured at $95^{\circ} \mathrm{C}$ for $5 \mathrm{~min}$, and then sequenced with an ABI3730XL sequencer. GeneMapper4.1 (AppliedBiosystems Co. Ltd, USA) was used to analyze the data.

2.6. Statistical Analysis. SPSS17.0 was used to analyze the data. The data was expressed as mean \pm SD. The HardyWeinberg (H-WE) equilibrium was used to detect the genotype frequency distribution of TagSNP loci of the PD-1 gene 


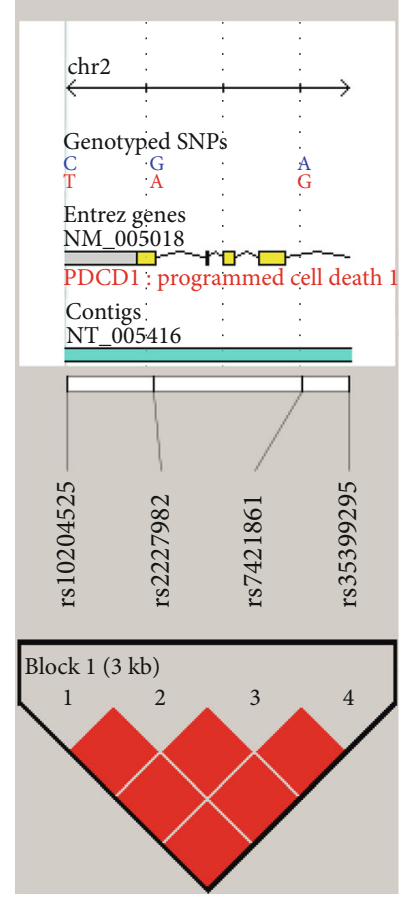

(a)

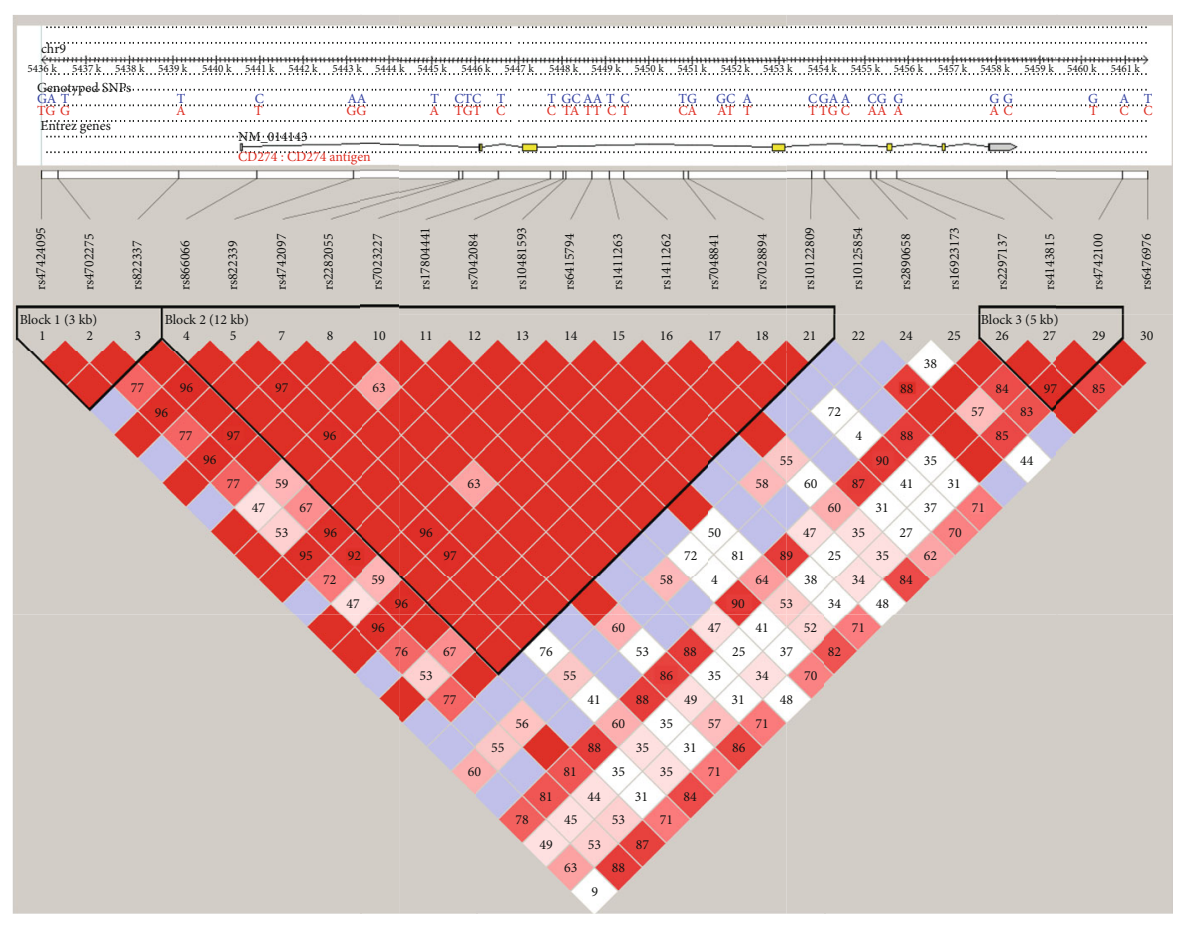

(b)

FIGURE 1: Structural map of linkage disequilibrium of SNPs in HapMap. (a) HapMap shows the linkage disequilibrium structure of PD-1 gene SNPs. (b) HapMap shows the linkage disequilibrium structure of PD-L1 gene SNPs.

and PD-L1 gene in the PCOS group and the control group, respectively. SHEsis (http://analysis.bio-x.cn/myAnalysis .php) was used to analyze the linkage disequilibrium and haplotype of the PD-1 gene SNP loci rs7421861 and rs10204525 and PD-L1 gene SNP loci rs2282055, rs2890658, rs702275, and rs10125854. The independent t test was used to compare the data between the two groups. Chisquare test was used to compare the genotype and allele frequency, and the correlation was analyzed by logistic regression [20]. The OR value and $95 \%$ confidence interval were calculated. $P<0.05$ was considered statistically significant.

\section{Results}

3.1. Clinical Information of PCOS Group and Control Group. A total of 330 patients with PCOS and 350 controls were included in this study. They were all from Xinjiang Uygur Autonomous Region, China. They were aged 20-39 years. The clinical data of included subjects are shown in Table 2. There was no statistically significant difference in age, BMI, WHR, and FSH between PCOS group and control group $(P>0.05)$. Statistical results showed that the levels of T, LH, LH/FSH, FBG, FNS, and HOMA-IR in the PCOS group were significantly higher than those in the control group (Table 2, $P<0.05$ ). These results indicate that the PCOS group has significant clinical differences compared with the normal control group.

3.2. Serum PD-1 and PD-L1 Level in Patients. ELISA was conducted to measure the serum levels of PD-1 and PD-L1. The results showed that the serum levels of PD-1 (Figure 2(a)) and PD-L1 (Figure 2(b)) in patients with PCOS were 0.76 $\pm 0.03 \mathrm{ng} / \mathrm{mL}$ and $1.41 \pm 0.04 \mathrm{ng} / \mathrm{mL}$, which were significantly lower than those in the control group $(1.19 \pm 0.03$ $\mathrm{ng} / \mathrm{mL}$ and $1.93 \pm 0.04 \mathrm{ng} / \mathrm{mL}$, respectively) $(P<0.01)$, suggesting that abnormalities of PD-1 and PD-L1 in the serum of PCOS patients may be related to the onset of PCOS.

3.3. PD-1 and PD-L1 Gene SNPs' H-WE Test. The SnaPshot typing results were shown in supplementary file 1 . H-WE test was used to detect the gene frequency distribution of PD-1 gene and PD-L1 gene TagSNP loci in PCOS group and control group, respectively. The results showed that the genotype distribution of the TagSNP loci of the PD-1 gene and PD-L1 gene in the PCOS group and the control group was consistent with the H-WE with good agreement (Table 3, $P>0.05$ ). Thus, these genotypes can be used for subsequent haplotype analysis.

3.4. SNPs of PD-1 and PD-L1 in Patients. Through HapMap analysis, we obtained 15 TagSNP loci of the PD-1 gene and PD-L1 gene. Among them, the allele frequency of the rs7421861 and rs10204525 in the PD-1 gene SNP loci and the rs2282055, rs2890658, rs702275, and rs10125854 in the PD-L1 SNP loci gene had statistically significant differences between the PCOS group and the control group (Table 4, $P<0.05)$. These results indicate that the SNPs of PD-1 gene and PD-L1 gene might be related to the pathogenesis of PCOS disease.

In addition, we found that the 15 TagSNP loci of PD-1 gene and PD-L1 gene in the PCOS group and the control group all conformed to H-WE. At the same time, by using 
TABLE 1: SNP sites and primer sequences of PD-1 gene and PD-L1 gene.

\begin{tabular}{|c|c|c|c|c|c|c|}
\hline SNP sites & Polymorphism & Primers & $\begin{array}{l}\text { Product } \\
\text { length }\end{array}$ & Extension & Products & Extension primer \\
\hline rs 10204525 & $(\mathrm{~A} / \mathrm{G})$ & $\begin{array}{c}\text { F: CAGGGAAGCTGAGGCA } \\
\text { GTAA } \\
\text { R: TTTCAGGAATGGGTTC } \\
\text { CAAG }\end{array}$ & $272 \mathrm{bp}$ & Forward & $(\mathrm{A} / \mathrm{G})$ & TTTTTTACCTAGGGCCCCCCAT \\
\hline rs4742095 & $(\mathrm{G} / \mathrm{T})$ & $\begin{array}{c}\text { F: CCCACAGCCCTTCTTG } \\
\text { TGAA } \\
\text { R: TCCAGAGTAGGATACT } \\
\text { ATAGCCAGT }\end{array}$ & $277 \mathrm{bp}$ & Reverse & $(\mathrm{A} / \mathrm{C})$ & $\begin{array}{l}\text { GGCAGTATGTTGACAGTATTTCAA } \\
\text { AG }\end{array}$ \\
\hline rs702275 & $(\mathrm{G} / \mathrm{T})$ & $\begin{array}{c}\text { F: TCTTCCTTGATTTCCT } \\
\text { TTTATCCA } \\
\text { R: GCAATGAAAAGCCACC } \\
\text { AGAT }\end{array}$ & $236 \mathrm{bp}$ & Reverse & $(\mathrm{A} / \mathrm{C})$ & $\begin{array}{c}\text { TTTTTTGAAAATCTTTAGGAGCTGTT } \\
\text { TCTGTAG }\end{array}$ \\
\hline rs822339 & $(\mathrm{C} / \mathrm{T})$ & $\begin{array}{c}\text { F: TAACTCTGGCCCAAGG } \\
\text { AAAA } \\
\text { R: TTTTGGTCTGTTTATG } \\
\text { TCACTGG }\end{array}$ & $250 \mathrm{bp}$ & Reverse & $(\mathrm{A} / \mathrm{G})$ & $\begin{array}{c}\text { TTTTTTTTTTTTTTTCATCTACAGGA } \\
\text { TAGACGGAAAGGA }\end{array}$ \\
\hline rs2282055 & $(\mathrm{A} / \mathrm{C})$ & $\begin{array}{c}\text { F: TGTAGGGGGAAAAAGC } \\
\text { ATTG } \\
\text { R: GCCCACAGCCACATAA } \\
\text { ACTT }\end{array}$ & $258 \mathrm{bp}$ & Reverse & $(\mathrm{G} / \mathrm{T})$ & $\begin{array}{c}\text { TTTTTTTTTTTTTTTTTTTTTTGTCA } \\
\text { GATTCTCCTTGCTCTGAAAT }\end{array}$ \\
\hline rs6415794 & $(\mathrm{A} / \mathrm{T})$ & $\begin{array}{c}\text { F: CCATCAATCTGAGGGC } \\
\text { TAACA } \\
\text { R: GATGTCATGAATGGAG } \\
\text { AAGCA }\end{array}$ & $264 \mathrm{bp}$ & Forward & $(\mathrm{A} / \mathrm{T})$ & TTATGTTGTATTTCTGGTCCCTGAT \\
\hline rs2890658 & $(\mathrm{A} / \mathrm{C})$ & $\begin{array}{c}\text { F: CCTGGGCAACAGAGAA } \\
\text { AGAC } \\
\text { R: GGAATGGCGAGATACC } \\
\text { TGTG }\end{array}$ & $306 \mathrm{bp}$ & Forward & $(\mathrm{A} / \mathrm{C})$ & $\begin{array}{l}\text { TTTTTTAAGAGGAAGTGAAATAAT } \\
\text { CAAGGC }\end{array}$ \\
\hline
\end{tabular}

TABle 2: Clinical characteristics of PCOS patients and control groups.

\begin{tabular}{lcccc}
\hline Items & PCOS $(n=330)$ & Control $(n=350)$ & $t$ & $P$ \\
\hline Age & $25.82 \pm 3.56$ & $26.23 \pm 3.41$ & -1.42 & 0.08 \\
BMI & $23.90 \pm 2.95$ & $23.50 \pm 2.17$ & 1.75 & 0.09 \\
WHR & $0.77 \pm 0.16$ & $0.75 \pm 0.16$ & 1.61 & 0.11 \\
FSH (IU/L) & $6.80 \pm 2.00$ & $6.58 \pm 1.81$ & 1.53 & 0.45 \\
T (nmol/L) & $1.23 \pm 0.70$ & $0.72 \pm 0.46$ & 11.49 & $0.01^{*}$ \\
LH (IU/L) & $11.95 \pm 4.96$ & $9.12 \pm 2.90$ & 9.10 & $0.02^{*}$ \\
LH/FSH & $1.75 \pm 0.83$ & $1.35 \pm 0.50$ & 7.59 & $0.03^{*}$ \\
FBG & $5.40 \pm 0.67$ & $5.01 \pm 0.46$ & 9.03 & $0.03^{*}$ \\
$(\mathrm{mmol} / \mathrm{L})$ & $13.58 \pm 5.82$ & $8.67 \pm 4.31$ & 12.48 & $<0.01^{*}$ \\
FNS (mIU/L) & $3.27 \pm 1.49$ & $1.93 \pm 1.00$ & 13.73 & $0.01^{*}$ \\
HOMA-IR & &
\end{tabular}

Note: PCOS: polycystic ovary syndrome; BMI: body mass index; WHR: waist hip ratio; FSH: follicle-stimulating hormone; LH: luteinizing hormone; T: testosterone; FBG: fasting blood glucose; FNS: fasting insulin; HOMA-IR: insulin resistance index. Data were shown as mean $\pm \mathrm{SD}$; ${ }^{*} P<0.05$.

the SHEsis software, we performed linkage disequilibrium and haplotype analyses for the six SNP sites with statistical differences in Table 4, including rs7421861 and rs10204525 of the PD-1 gene SNP loci and the rs2282055, rs2890658, rs702275, and, rs10125854 of the PD-L1 gene SNP loci. The results showed that the haplotype TT of rs7421861 and rs10204525 of the PD-1 SNP loci had a haplotype frequency of 0.45 in the control group and of 0.36 in the PCOS group. The TT haplotype distribution frequency in the PCOS group was significantly lower than that in the control group (Table 5; $\mathrm{OR}=0.67,95 \% \mathrm{CI}=0.54-0.84$, and $P<0.05$ ). Moreover, in the PCOS group and the control group, there were significant differences in the haplotypes GAAA, TAAA, GAAC, TAAC, GAGC, GCAA, TCAA, GCGA, TCGA, GCAC, and TCGC of the rs2282055, rs2890658, rs702275, and rs10125854 SNP loci of the PD-L1 gene (Table 6, $P<0.05)$. The above results suggest that the haplotypes of the SNP loci of PD-1 and PD-L1 genes are related to the occurrence and development of PCOS disease.

\section{Discussion}

Chronic inflammation has been a uniform clinical feature in patients with PCOS. The PD-1, a member of the B7/CD28 costimulatory molecule family, is a cosuppression signal molecule that inhibits $\mathrm{T}$ cell activation [21]. PD-L1, PD-1 ligand, can induce $\mathrm{T}$ cell apoptosis and stimulate cells to secrete IL-10, thereby mediating immunosuppressive effects [22]. The physiological function of PD-L1 is to regulate the inflammatory response and limit tissue damage. Thus, the 


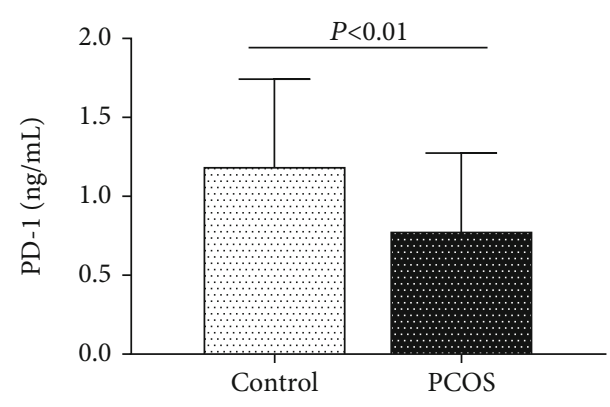

(a)

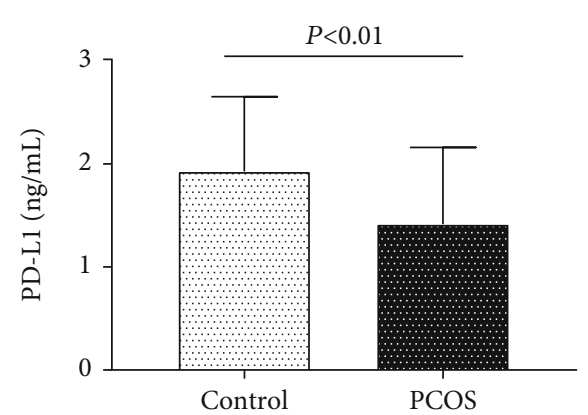

(b)

Figure 2: Serum levels of PD-1 and PD-L1 in PCOS and control groups. (a) PD-1 levels in the serum of PCOS group and control group. (b) PD-L1 levels in the serum PCOS and control groups.

TABLE 3: H-WE equilibrium test of genotype distribution of SNP loci in PD-1 and PD-L1 genes.

\begin{tabular}{lccccc}
\hline \multirow{2}{*}{ Gene } & \multirow{2}{*}{ TagSNP } & \multicolumn{2}{c}{ PCOS } & \multicolumn{2}{c}{ Control } \\
& rs6415794 & 0.95 & 0.33 & 3.18 & 0.07 \\
& rs822339 & 1.50 & 0.22 & 1.36 & 0.24 \\
& rs17804441 & 1.53 & 0.22 & 0.19 & 0.66 \\
& rs2282055 & 1.59 & 0.21 & 0.18 & 0.67 \\
& rs4143815 & 1.30 & 0.26 & 1.41 & 0.24 \\
PD-L1 gene & rs2890658 & 3.54 & 0.06 & 1.69 & 0.20 \\
& rs2297137 & 0.15 & 0.70 & 2.44 & 0.12 \\
& rs10125854 & 0.00 & 0.98 & 0.95 & 0.33 \\
& rs6476976 & 1.53 & 0.22 & 3.20 & 0.07 \\
& rs702275 & 2.57 & 0.11 & 1.41 & 0.24 \\
& rs16923173 & 2.93 & 0.09 & 3.33 & 0.07 \\
& rs4742095 & 0.61 & 0.43 & 2.97 & 0.09 \\
& rs7421861 & 0.52 & 0.48 & 2.97 & 0.09 \\
& rs2227982 & 0.14 & 0.71 & 1.28 & 0.26 \\
& rs10204525 & 0.25 & 0.62 & 1.80 & 0.18 \\
\hline
\end{tabular}

Note: PCOS: polycystic ovary syndrome; SNP: single nucleotide polymorphism. $P>0.05$ is considered as good agreement with $\mathrm{H}-\mathrm{WE}$ equilibrium test.

interaction between PD-1 and PD-L1 can prevent excessive inflammation and suppress the immune response.

In this study, we tested the levels of PD-1 and PD-L1 in serum. The results showed that compared with the control group, the levels of PD-1 and PD-L1 were lower in the serum of PCOS patients, which is consistent with the study of $\mathrm{Ni}$ et al. [23]. The low levels of PD-1 and PD-L1 in the serum of PCOS patients may be related to their inability to effectively inhibit $\mathrm{T}$ and $\mathrm{B}$ cell function and proliferation, thus leading to the pathogenesis of PCOS. However, whether the decrease in PD-1 and PD-L1 levels can be used as an immunological diagnosis and treatment index for PCOS disease requires further research.

Mounting evidence suggests that PCOS might be a complex multigenic disorder strongly influenced by epigenetic and environmental factors, including diet and lifestyle factors [24]. Pedigree studies have shown that PCOS has significant family clustering characteristics $[25,26]$. At present, the largest twin studies in PCOS have found that the incidence of PCOS was twice as high in monozygotic twins as in dizygotic twins, indicating that genetic factors play a very important role in PCOS pathogenesis [27]. In this study, we used SnaPshot typing to detect PD-1 and PD-L1 gene polymorphisms in PCOS and analyzed the correlation between PD-1 and PD-L1 gene polymorphisms and PCOS. The results showed that the allele frequencies of the PD-1 gene SNP loci (rs7421861 and rs10204525) and PD-L1 gene SNP loci (rs2282055, rs2890658, rs702275, and rs10125854) were significantly different between the two groups, indicating that these SNP loci may be related to the development of PCOS.

In addition, in order to investigate whether the frequency distribution of genes and genotypes of PCOS patients and control groups has reached genetic balance and to understand whether they are representative of the population, we use the $\mathrm{H}-\mathrm{WE}$ to detect the genotype frequency distribution of PD-1 gene SNP loci rs7421861 and rs10204525 and PDL1 gene SNP loci rs2282055, rs2890658, rs702275, and rs10125854. H-WE test can reflect the representative of the population $[28,29]$. The results confirmed that these SNP loci conformed to H-WE. These results showed that these SNP loci were not only significantly different between the PCOS group and the control group, but also were representative of the population.

In this study, we analyzed the linkage disequilibrium and haplotype between SNP loci of the PD-1 gene. The results showed that there was a linkage disequilibrium between rs10204525 and rs7421861 of the PD-1 gene SNP loci. At the same time, the haplotype TT of PD-1 gene at rs10204525 and rs7421861 loci was less frequently distributed in the PCOS group than in the control group. It is reported that PD-1 gene polymorphism is related to some inflammatory diseases and autoimmune diseases, such as allergic asthma [30]. The PD-1 gene polymorphism rs2227981 is associated with tumor occurrence, including digestive system tumors and female-specific tumors [31]. PD-1 polymorphism is associated with susceptibility to diseases such as gastric cancer, clear cell renal cancer, HBV, and HCV [32-34]. After the PD-1 gene is knocked out, its original negative regulatory effect would be lost, resulting in increased levels of inflammatory factors, which promotes the imbalance of proinflammatory and anti-inflammatory 
TABLE 4: Allele frequency distributions of PD-L1 and PD-1 gene SNP loci in the PCOS and control groups.

\begin{tabular}{|c|c|c|c|c|c|c|}
\hline Gene & SNP & Allele & $\operatorname{PCOS}(n=330)$ & Control $(n=350)$ & $\chi^{2}$ & $P$ \\
\hline \multirow{12}{*}{ PD-L1 gene } & rs6415794 & $\begin{array}{l}\mathrm{T} \\
\mathrm{A}\end{array}$ & $\begin{array}{l}456(69.05) \\
204(30.95)\end{array}$ & $\begin{array}{l}469(66.96) \\
231(33.04)\end{array}$ & 0.68 & 0.41 \\
\hline & rs822339 & $\begin{array}{l}\mathrm{C} \\
\mathrm{T}\end{array}$ & $\begin{array}{l}424(64.29) \\
236(35.71)\end{array}$ & $\begin{array}{l}420(60.00) \\
280(40.00)\end{array}$ & 2.65 & 0.10 \\
\hline & rs17804441 & $\begin{array}{l}A \\
G\end{array}$ & $\begin{array}{l}447(67.71) \\
213(32.29)\end{array}$ & $\begin{array}{l}486(69.42) \\
214(30.58)\end{array}$ & 0.46 & 0.49 \\
\hline & rs2282055 & $\begin{array}{l}\mathrm{C} \\
\mathrm{A}\end{array}$ & $\begin{array}{l}348(52.67) \\
312(47.33)\end{array}$ & $\begin{array}{l}433(61.88) \\
267(38.12)\end{array}$ & 11.77 & $<0.01^{*}$ \\
\hline & rs4143815 & $\begin{array}{l}\mathrm{C} \\
\mathrm{G}\end{array}$ & $\begin{array}{l}468(70.98) \\
192(29.02)\end{array}$ & $\begin{array}{l}489(69.86) \\
211(30.14)\end{array}$ & 0.20 & 0.65 \\
\hline & rs2890658 & $\begin{array}{l}\mathrm{A} \\
\mathrm{C}\end{array}$ & $\begin{array}{l}440(66.67) \\
220(33.33)\end{array}$ & $\begin{array}{l}430(61.45) \\
270(38.55)\end{array}$ & 4.01 & $0.04^{*}$ \\
\hline & rs2297137 & $\begin{array}{l}\mathrm{G} \\
\mathrm{A}\end{array}$ & $\begin{array}{l}474(71.88) \\
186(28.12)\end{array}$ & $\begin{array}{l}473(67.54) \\
227(32.46)\end{array}$ & 3.02 & 0.08 \\
\hline & rs10125854 & $\begin{array}{l}A \\
G\end{array}$ & $\begin{array}{l}406(61.46) \\
254(38.54)\end{array}$ & $\begin{array}{l}471(67.25) \\
229(32.75)\end{array}$ & 4.97 & $0.03^{*}$ \\
\hline & rs6476976 & $\begin{array}{l}\mathrm{C} \\
\mathrm{T}\end{array}$ & $\begin{array}{l}447(67.71) \\
213(32.29)\end{array}$ & $\begin{array}{l}487(69.57) \\
213(30.43)\end{array}$ & 0.55 & 0.46 \\
\hline & rs702275 & $\begin{array}{l}\mathrm{T} \\
\mathrm{G}\end{array}$ & $\begin{array}{l}315(47.77) \\
345(52.23)\end{array}$ & $\begin{array}{c}383(54.78) \\
317(45.22)\end{array}$ & 6.68 & $0.01^{*}$ \\
\hline & rs16923173 & $\begin{array}{l}\mathrm{G} \\
\mathrm{A}\end{array}$ & $\begin{array}{l}438(66.37) \\
222(33.63)\end{array}$ & $\begin{array}{l}449(64.21) \\
251(35.79)\end{array}$ & 0.70 & 0.40 \\
\hline & rs4742095 & $\begin{array}{l}\mathrm{G} \\
\mathrm{T}\end{array}$ & $\begin{array}{c}583(88.39) \\
77(11.61)\end{array}$ & $\begin{array}{c}606(86.52) \\
94(13.48)\end{array}$ & 1.08 & 0.30 \\
\hline \multirow{3}{*}{ PD-1 gene } & rs7421861 & $\begin{array}{l}\mathrm{T} \\
\mathrm{C}\end{array}$ & $\begin{array}{l}396(59.97) \\
264(40.03)\end{array}$ & $\begin{array}{l}457(65.22) \\
243(34.78)\end{array}$ & 4.00 & $0.04^{*}$ \\
\hline & rs2227982 & $\begin{array}{l}\mathrm{T} \\
\mathrm{C}\end{array}$ & $\begin{array}{l}371(56.25) \\
289(43.75)\end{array}$ & $\begin{array}{l}387(55.22) \\
313(44.78)\end{array}$ & 0.15 & 0.70 \\
\hline & rs10204525 & $\begin{array}{l}\mathrm{T} \\
\mathrm{C}\end{array}$ & $\begin{array}{l}370(56.10) \\
290(43.90)\end{array}$ & $\begin{array}{l}431(61.59) \\
269(38.41)\end{array}$ & 4.23 & $0.04^{*}$ \\
\hline
\end{tabular}

Note: PCOS: polycystic ovary syndrome; SNP: single nucleotide polymorphism. ${ }^{*} P<0.05$.

TABLE 5: Haplotype frequency distribution of rs7421861 and rs10204525 of PD-1 gene.

\begin{tabular}{lccccc}
\hline Haplotype & Control (frequency) & PCOS (frequency) & $\chi^{2}$ & $P$ & 0.55 \\
\hline CC & $129.99(0.19)$ & $130.97(0.20)$ & 0.36 & 3.61 & 0.06 \\
TC & $113.49(0.16)$ & $133.23(0.20)$ & 3.54 & 0.06 \\
CT & $138.85(0.20)$ & $158.76(0.24)$ & 12.64 & $<0.01^{*}$ & $0.67(0.54-0.84)$ \\
TT & $317.67(0.45)$ & $237.04(0.36)$ &
\end{tabular}

Note: PCOS: polycystic ovary syndrome. ${ }^{*} P<0.05$.

cytokines and thereby promotes the occurrence of related diseases [35]. PD-1 is also related to immune dysfunction [36]. Moreover, inflammation is one of the clinical features of PCOS women [37]. Thus, we believe that the immune response involving $\mathrm{PD}-1$ gene polymorphism is related to the pathogenicity of PCOS. When the T allele and $\mathrm{T}$ allele of PD-1 gene are mutated at the same time, haplotype TT is a protective factor for the occurrence of PCOS disease. The haplotype of PD-1 gene is related to the occurrence and development of PCOS disease, which indicates that the PD1 gene polymorphism is related to the pathogenesis of PCOS.
In the linkage disequilibrium and haplotype analysis of the PD-L1 gene SNP loci rs2282055, rs2890658, rs10125854, and rs702275, the results showed that there was a linkage disequilibrium between the PD-L1 gene SNP loci rs2282055, rs2890658, rs10125854, and rs702275. And the haplotype TAAA, GAAC, GAGC, GCAA, and TCGA frequencies in the PCOS group were significantly higher than the control group. However, the haplotype GAAA, TAAC, TCAA, GCGA, GCAC, and TCGC frequencies were significantly lower in the PCOS group than in the control group. Studies have reported that the PD-L1 gene rs4143815 may 
TABLE 6: Haplotype frequency distribution of rs2282055, rs2890658, rs702275, and rs10125854 loci of the PD-L1 gene.

\begin{tabular}{|c|c|c|c|c|c|}
\hline Haplotype & Control (frequency) & PCOS (frequency) & $x^{2}$ & $P$ & OR (95\% CI) \\
\hline GAAA & $123.87(0.18)$ & $44.38(0.07)$ & 35.22 & $<0.01^{*}$ & $0.35(0.24 \sim 0.50)$ \\
\hline TAAA & $38.56(0.06)$ & $127.81(0.19)$ & 64.70 & $<0.01^{*}$ & $4.35(2.96 \sim 6.31)$ \\
\hline GAAC & $27.11(0.04)$ & $59.06(0.09)$ & 16.10 & $<0.01^{*}$ & $2.54(1.59 \sim 4.06)$ \\
\hline TAAC & $49.51(0.07)$ & $10.86(0.02)$ & 22.53 & $<0.01^{*}$ & $0.23(0.12 \sim 0.44)$ \\
\hline GAGC & $18.26(0.03)$ & $38.30(0.06)$ & 9.51 & $<0.01^{*}$ & $2.39(1.35 \sim 4.22)$ \\
\hline GCAA & $62.45(0.09)$ & $93.08(0.14)$ & 10.53 & $<0.01^{*}$ & $1.75(1.24 \sim 2.46)$ \\
\hline TCAA & $116.08(0.17)$ & $48.16(0.07)$ & 25.41 & $<0.01^{*}$ & $0.41(0.29 \sim 0.59)$ \\
\hline GCGA & $51.56(0.07)$ & $15.32(0.02)$ & 17.44 & $<0.01^{*}$ & $0.31(0.17 \sim 0.55)$ \\
\hline TCGA & $28.12(0.04)$ & $86.84(0.13)$ & 39.08 & $<0.01^{*}$ & $3.78(2.43 \sim 5.88)$ \\
\hline GCAC & $29.03(0.04)$ & $7.74(0.01)$ & 10.83 & $<0.01^{*}$ & $0.28(0.13 \sim 0.63)$ \\
\hline TCAC & $24.73(0.03)$ & $14.56(0.02)$ & 1.59 & 0.21 & \\
\hline TCGC & $121.82(0.17)$ & $0.41(0.00)$ & 121.81 & $<0.01^{*}$ & $0.00(0.00 \sim 0.02)$ \\
\hline
\end{tabular}

Note: PCOS: polycystic ovary syndrome. ${ }^{*} P<0.05$.

be associated with an increased risk of gastric cancer [38, 39] and non-small-cell lung cancer $[40,41]$, which may be caused by increased PD-L1 expression and suppression of immune tumor surveillance [42]. Women with PCOS have an increased risk of endometrial cancer, ovarian cancer, endocrine adenocarcinoma, pancreatic cancer, and other cancers [43]. We believe that the polymorphism of the PD-L1 gene affects the expression of $\mathrm{PD}-\mathrm{L} 1$, which in turn promotes the onset of PCOS. These results suggest that haplotypes TAAA, GAAC, GAGC, GCAA, and TCGA might be susceptibility factors for the occurrence of PCOS, while haplotypes GAAA, TAAC, TCAA, GCGA, GCAC, and TCGC might be protective factors for the occurrence of PCOS. The haplotype of PD-L1 gene SNP loci is related to the occurrence and development of PCOS which indicates that the polymorphism of $\mathrm{PD}-\mathrm{L} 1$ gene is related to the pathogenesis of PCOS.

However, there are still some limitations in the study. First, the number of cases in this study is limited. Second, the specific pathways and mechanisms of PD-1 gene and PD-L1 gene in the pathogenesis of PCOS were not investigated. Further studies with large sample size are still needed to reveal the underlying mechanisms.

\section{Conclusions}

In summary, in this study, we reported for the first time that $\mathrm{PD}-1$ gene and PD-L1 gene may be involved in the pathogenesis of PCOS. Our results showed that the genotype distribution, allele frequency, and haplotype of the PD-1 gene SNP loci rs10204525 and rs7421861 and PD-L1 gene rs2282055, rs2890658, rs10125854, and rs702275 were all related to the pathogenesis of PCOS. In the follow-up studies, we will further explore the correlation of PD-1 and PD-L1 gene polymorphisms with the clinical characteristics of PCOS. These results will help screen and protect susceptible populations at the genetic level, will also provide theoretical basis for individualized diagnosis and treatment programs for PCOS patients, and will provide a basis for developing novel biological markers for early screening and diagnosis of PCOS.

\section{Data Availability}

The data that support the findings of this study are available on request from the corresponding author.

\section{Conflicts of Interest}

The authors declare that there is no conflict of interest regarding the publication of this paper.

\section{Authors' Contributions}

Rui Han and Xiaoyun Gong contributed equally to this work.

\section{Acknowledgments}

This work was supported by the State Key Laboratory of Pathogenesis, Prevention and Treatment of High Incidence Diseases in Central Asia Fund (grant number SKL-HIDCA2020-JZ10) and the Regional Science Fund Project of National Natural Science Foundation of China (grant number 81960289).

\section{Supplementary Materials}

Supplementary file 1 . The SnaPshot typing results. (Supplementary Materials)

\section{References}

[1] R. Azziz, K. S. Woods, R. Reyna, T. J. Key, E. S. Knochenhauer, and B. O. Yildiz, "The prevalence and features of the polycystic ovary syndrome in an unselected population," The Journal of Clinical Endocrinology and Metabolism, vol. 89, no. 6, pp. 2745-2749, 2004.

[2] M. T. Sheehan, "Polycystic ovarian syndrome: diagnosis and management," Clinical Medicine \& Research, vol. 2, no. 1, pp. 13-27, 2004. 
[3] R. J. Norman, D. Dewailly, R. S. Legro, and T. E. Hickey, "Polycystic ovary syndrome," Lancet, vol. 370, no. 9588, pp. 685-697, 2007.

[4] E. Vassilatou, "Nonalcoholic fatty liver disease and polycystic ovary syndrome," World Journal of Gastroenterology, vol. 20, no. 26, pp. 8351-8363, 2014.

[5] Y. Huang, J. Ding, and X. Li, "Association between single nucleotide polymorphisms of Lhcgr gene, Thada gene, Denneia gene and polycystic ovary syndrome in Xinjiang," Journal of Xinjiang Medical University, vol. 39, no. 8, pp. 997-1003, 2016.

[6] N. Xita, I. Georgiou, and A. Tsatsoulis, "The genetic basis of polycystic ovary syndrome," European Journal of Endocrinology, vol. 147, no. 6, pp. 717-725, 2002.

[7] Z. J. Chen, H. Zhao, L. He et al., "Genome-wide association study identifies susceptibility loci for polycystic ovary syndrome on chromosome 2p16.3, 2p21 and 9q33.3," Nature Genetics, vol. 43, no. 1, pp. 55-59, 2011.

[8] B. T. Fife and K. E. Pauken, "The role of the Pd-1 pathway in autoimmunity and peripheral tolerance," Annals of the New York Academy of Sciences, vol. 1217, no. 1, pp. 45-59, 2011.

[9] K. H. Chua, L. Lian, X. Sim, T. Cheah, and T. Lau, "Association between Pdcd1 gene polymorphisms and risk of systemic lupus erythematosus in three main ethnic groups of the Malaysian population," International Journal of Molecular Sciences, vol. 16, no. 12, pp. 9794-9803, 2015.

[10] H. Chen and M. Wei, "Correlation between Pd-1 gene polymorphisms and serum Pd-1, Pd-L1 levels and clinical characteristics in patients with renal cancer," International Medicine and Health Guidance News, vol. 22, no. 15, pp. 2255-2257, 2016.

[11] M. R. Haghshenas, M. H. Dabbaghmanesh, A. Miri, A. Ghaderi, and N. Erfani, "Association of Pdcd1 gene markers with susceptibility to thyroid cancer," Journal of Endocrinological Investigation, vol. 40, no. 5, pp. 481-486, 2017.

[12] L. Zolfaghari, G. Solgi, M. Nafar et al., "Association of programmed cell death 1 and programmed cell death 1 ligand gene polymorphisms with delayed graft function and acute rejection in kidney allograft recipients," Iranian Journal of Kidney Diseases, vol. 9, no. 2, pp. 138-145, 2015.

[13] M. Hashemi, S. Karami, S. Sarabandi et al., "Association between Pd-1 and Pd-L1 polymorphisms and the risk of cancer: a meta-analysis of case-control studies," Cancers (Basel), vol. 11, no. 8, p. 1150, 2019.

[14] Q. Yang, Y. Liu, D. Liu, Y. Zhang, and K. Mu, "Association of polymorphisms in the programmed cell death $1(\mathrm{Pd}-1)$ and Pd-1 ligand genes with ankylosing spondylitis in a Chinese population," Clinical and Experimental Rheumatology, vol. 29, no. 1, pp. 13-18, 2011.

[15] S. Chen, Y. Li, C. Deng et al., "The associations between Pd-1, Ctla-4 gene polymorphisms and susceptibility to ankylosing spondylitis: a meta-analysis and systemic review," Rheumatology International, vol. 36, no. 1, pp. 33-44, 2016.

[16] Y. Ma, X. Liu, J. Zhu et al., "Polymorphisms of co-inhibitory molecules (Ctla-4/Pd-1/Pd-L1) and the risk of non-small cell lung cancer in a Chinese population," International Journal of Clinical and Experimental Medicine, vol. 8, no. 9, pp. 16585-16591, 2015.

[17] S. Cheng, J. Zheng, J. Zhu et al., "Pd-L1 gene polymorphism and high level of plasma soluble Pd-L1 protein may be associated with non-small cell lung cancer," The International Journal of Biological Markers, vol. 30, no. 4, pp. e364-e368, 2015.
[18] The Rotterdam ESHRE/ASRM-sponsored PCOS consensus workshop group, "Revised 2003 consensus on diagnostic criteria and long-term health risks related to polycystic ovary syndrome (Pcos)," Human Reproduction, vol. 19, no. 1, pp. 41-47, 2004.

[19] D. P. Chen, Y. H. Wen, J. J. Lu, C. P. Tseng, and W. T. Wang, "Rapid rare ABO blood typing using a single PCR based on a multiplex SNaPshot reaction," Journal of the Formosan Medical Association, vol. 118, no. 1, pp. 395-400, 2019.

[20] R. Han, K. Feng, and B. Liu, "Implementation of chi-square and logistic regression analysis of single nucleotide polymorphism data in SPSS statistical software," Medical Journal of the Ministry of General Equipment, vol. 10, no. 2, pp. 63-65, 2008.

[21] E. Hui, J. Cheung, J. Zhu et al., "T cell costimulatory receptor $\mathrm{Cd} 28$ is a primary target for Pd-1-mediated inhibition," Science, vol. 355, no. 6332, pp. 1428-1433, 2017.

[22] L. Chen and X. Han, "Anti-Pd-1/Pd-L1 therapy of human cancer: past, present, and future," The Journal of Clinical Investigation, vol. 125, no. 9, pp. 3384-3391, 2015.

[23] L. Ni and L. Jin, "Preliminary study on the involvement of interleukin 18 and interleukin 10 in the pathogenesis of polycystic ovary syndrome," Chinese Journal of Eugenics and Genetics, vol. 18, no. 7, pp. 126-127, 2010.

[24] H. F. Escobar-Morreale, "Polycystic ovary syndrome: definition, aetiology, diagnosis and treatment," Nature Reviews. Endocrinology, vol. 14, no. 5, pp. 270-284, 2018.

[25] R. S. Legro, R. Bentley-Lewis, D. Driscoll, S. C. Wang, and A. Dunaif, "Insulin resistance in the sisters of women with polycystic ovary syndrome: association with hyperandrogenemia rather than menstrual irregularity," The Journal of Clinical Endocrinology and Metabolism, vol. 87, no. 5, pp. 2128 2133, 2002.

[26] P. Amato and J. L. Simpson, "The genetics of polycystic ovary syndrome," Best Practice \& Research. Clinical Obstetrics \& Gynaecology, vol. 18, no. 5, pp. 707-718, 2004.

[27] C. E. Cesta, R. Kuja-Halkola, K. Lehto, A. N. Iliadou, and M. Landén, "Polycystic ovary syndrome, personality, and depression: a twin study," Psychoneuroendocrinology, vol. 85, pp. 63-68, 2017.

[28] X. Zhang, Y. Gu, Y. Li et al., "Association of rs944289, rs965513, and rs1443434 in Titf1/Titf2 with risks of papillary thyroid carcinoma and with nodular goiter in northern Chinese Han populations," International Journal of Endocrinology, vol. 2020, Article ID 4539747, 9 pages, 2020.

[29] V. O. Osunkalu, I. A. Taiwo, C. C. Makwe, and R. A. Quao, "Methylene tetrahydrofolate reductase and methionine synthase gene polymorphisms as genetic determinants of preeclampsia," Pregnancy Hypertens, vol. 20, pp. 7-13, 2020.

[30] E. V. Dmitrieva-Zdorova, M. V. Gabaeva, Y. A. Seregin, N. V. Bodoev, and O. E. Voronko, "PDCD1 PD-1.3 polymorphism and allergic bronchial asthma in Russian and Buryat patients," The Journal of Asthma, vol. 54, no. 1, pp. 46-52, 2017.

[31] U. Mamat and M. Arkinjan, "Association of programmed death-1 gene polymorphism rs2227981 with tumor: evidence from a meta analysis," International Journal of Clinical and Experimental Medicine, vol. 8, no. 8, pp. 13282-13288, 2015.

[32] S. Savabkar, P. Azimzadeh, V. Chaleshi, E. Nazemalhosseini Mojarad, and H. A. Aghdaei, "Programmed death-1 gene polymorphism (PD-1.5 C/T) is associated with gastric cancer," Gastroenterology and Hepatology From Bed to Bench, vol. 6, no. 4, pp. 178-182, 2013. 
[33] Q. Xue, Y. Guo, and Y. Ma, "Correlation between PD-1 gene polymorphism and HBV infection in Jining, Shandong," Medical Laboratory and Clinical, vol. 27, no. 2, pp. 1-3, 2016.

[34] L. Kong, Y. Nan, and Y. Zhang, "Relationship between polymorphism of programmed cell death receptor 1 gene and chronic HCV infection and antiviral efficacy," Journal of Clinical Hepatology, vol. 32, no. 9, pp. 1721-1724, 2016.

[35] G. Fu, C. Yizhan, and Y. Zhong, "The relationship between inflammation and atrial electrical remodeling after C-1bl6 mouse PD-1 gene knockout," Progress in Modern Biomedicine, vol. 14, no. 2, pp. 4249-4251, 2014.

[36] J. Wu, L. Wang, and C. Ling, "The expression and significance of PD-1 in perimenopausal women," China Medical Science, vol. 5, no. 9, pp. 13-16, 57, 2015.

[37] M. Pawelczak, J. Rosenthal, S. Milla, Y. H. Liu, and B. Shah, "Evaluation of the pro-inflammatory cytokine tumor necrosis factor- $A$ in adolescents with polycystic ovary syndrome," Journal of Pediatric and Adolescent Gynecology, vol. 27, no. 6, pp. 356-359, 2014.

[38] W. Wang, F. Li, Y. Mao et al., “A miR-570 binding site polymorphism in the $\mathrm{B} 7-\mathrm{H} 1$ gene is associated with the risk of gastric adenocarcinoma," Human Genetics, vol. 132, no. 6, pp. 641-648, 2013.

[39] L. H. Tao, X. R. Zhou, F. C. Li et al., "A polymorphism in the promoter region of $\mathrm{PD}-\mathrm{L} 1$ serves as a binding-site for SP1 and is associated with PD-L1 overexpression and increased occurrence of gastric cancer," Cancer Immunology, Immunotherapy, vol. 66, no. 3, pp. 309-318, 2017.

[40] W. Du, J. Zhu, Y. Chen et al., "Variant SNPs at the microRNA complementary site in the $\mathrm{B} 7-\mathrm{H} 13^{\prime}$-untranslated region increase the risk of non-small cell lung cancer," Molecular Medicine Reports, vol. 16, no. 3, pp. 2682-2690, 2017.

[41] T. Nomizo, H. Ozasa, T. Tsuji et al., "Clinical impact of single nucleotide polymorphism in PD-L1 on response to nivolumab for advanced non-small-cell lung cancer patients," Scientific Reports, vol. 7, no. 1, article 45124, 2017.

[42] X. L. Shi, S. Mancham, B. E. Hansen et al., "Counter-regulation of rejection activity against human liver grafts by donor PD-L1 and recipient PD-1 interaction," Journal of Hepatology, vol. 64, no. 6, pp. 1274-1282, 2016.

[43] W. Yin, H. Falconer, L. Yin, L. Xu, and W. Ye, "Association between polycystic ovary syndrome and cancer risk," JAMA Oncology, vol. 5, no. 1, pp. 106-107, 2019. 